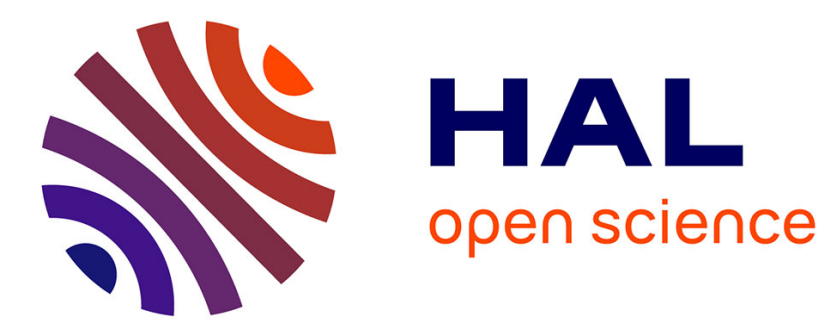

\title{
Dimensioning the Equipment of a Wave Farm: Energy Storage and Cables
}

\author{
Anne Blavette, Dara O'Sullivan, Tony Lewis, Michael Egan
}

\section{To cite this version:}

Anne Blavette, Dara O'Sullivan, Tony Lewis, Michael Egan. Dimensioning the Equipment of a Wave Farm: Energy Storage and Cables. EVER'13, 2013, Monaco, Monaco. hal-01266004

\section{HAL Id: hal-01266004 https://hal.science/hal-01266004}

Submitted on 26 Jan 2018

HAL is a multi-disciplinary open access archive for the deposit and dissemination of scientific research documents, whether they are published or not. The documents may come from teaching and research institutions in France or abroad, or from public or private research centers.
L'archive ouverte pluridisciplinaire HAL, est destinée au dépôt et à la diffusion de documents scientifiques de niveau recherche, publiés ou non, émanant des établissements d'enseignement et de recherche français ou étrangers, des laboratoires publics ou privés. 


\section{Dimensioning the Equipment of a Wave Farm: Energy Storage and Cables}

\author{
Anne Blavette, Dara L. O'Sullivan and Tony W. Lewis \\ Hydraulics \& Maritime Research Centre \\ University College Cork \\ Cork, Ireland \\ Email: anne.blavette@umail.ucc.ie
}

\author{
Michael G. Egan \\ Department of Electrical Engineering \\ University College Cork \\ Cork, Ireland
}

\begin{abstract}
Still largely untapped, wave energy is particularly abundant and may represent an important share in the energy mix of many countries in the future. However, the power fluctuations generated by most wave energy converters with little to no storage means or without suitable control strategies may deteriorate the power quality of the local network to which wave farms will be connected. They may in particular generate an excessive level of flicker. The minimum amount of storage required for a wave farm to be grid compliant with respect to typical flicker requirements was investigated and is presented in the first part of this study. Besides giving rise to power quality issues, the rapid and high amplitude power peaks generated by wave devices may also render more complex the optimal dimensioning of the wave farm electrical components, whose cost is highly dependent on their power rating. This statement applies also to submarine cables, as the maximum current flowing potentially through them seems to be no longer a relevant criterion for determining their optimal current rating. Hence, the second part of the presented study focuses on the minimum current rating required from a submarine cable to avoid its thermal overloading.
\end{abstract}

\section{INTRODUCTION}

Flicker was identified as an important issue which may require the use of energy storage means or dedicated control strategies to reduce its level at the point of common coupling below the limits enforced by the power system operators [1]. Several studies have investigated the efficiency of different energy storage means in reducing the power standard deviation [2] and the flicker level [3], [4] generated by a small to medium size wave farm. However, in all cases, the farm was connected to a relatively weak grid, which is more prone to be negatively affected by the injection of fluctuating power, or to an extremely strong grid which was not affected, as expected. Hence, in all these cases, the maximum power output by the wave farm was either in the same order of magnitude or negligible compared to the short-circuit level of the considered grids. It must be noted that the minimum energy capacity required for maintaining the flicker level below the grid operator's limit was also investigated, regardless of the grid strength, but only in the frame of a small size farm [5]. Hence, this paper investigates the minimum characteristics required from a storage means for maintaining the flicker level generated by a medium size wave farm below the typically enforced limits.
Flicker generation being highly dependent on the network grid strength, the study was performed for a wide range of typical strength levels, both in terms of short-circuit level $\left(S_{S C}\right)$ and of impedance angle $\Psi_{k}=\arctan (X / R)$. As these limits enforced by grid operators may vary significantly from one country or region to another, a survey was conducted in [1] to determine both the most permissive and the most stringent limits among the requirements enforced by several grid operators. These two limits were retained for the study presented in this paper.

The experience gained from the wind energy industry as well as studies focusing on wave energy have demonstrated that exploiting the entire amount of wave energy available at a given site, including during the periods presenting the most extreme wave conditions, may be detrimental from an economical perspective. Besides requiring a more robust wave energy converter design, harnessing energy during the most energetic sea-states demands also a higher rated, and thus more expensive, power transmission equipment, in particular regarding the submarine export cables. A study focusing on wind energy suggested power generation curtailment during highly energetic conditions as a relevant way to decrease the wind farm's capital expenditure by reducing the cables' rating. It demonstrated indeed that the optimal power rating, from an economical point of view, of the wind farm's export cable was equal to $89 \%$ of the rated power [6].

In similar fashion, the additional contribution of highly energetic sea-states to the annual electricity production of a wave farm is relatively negligible [7]. Power generation curtailment may thus be also envisaged as a way to optimize the farm's design. An approach, which is complementary to the curtailment method, consists of estimating the minimum cables' rating based on their dynamic thermal response. It is important to bear in mind that the current rating of cable is determined from the maximum temperature at which its different components can be safely operated. Hence, temperature constitutes one of the main limiting factors for power transmission through a cable. However, the maximum current rating of a cable is usually determined based on steady-state calculations (thus assuming a constant current) which are not 


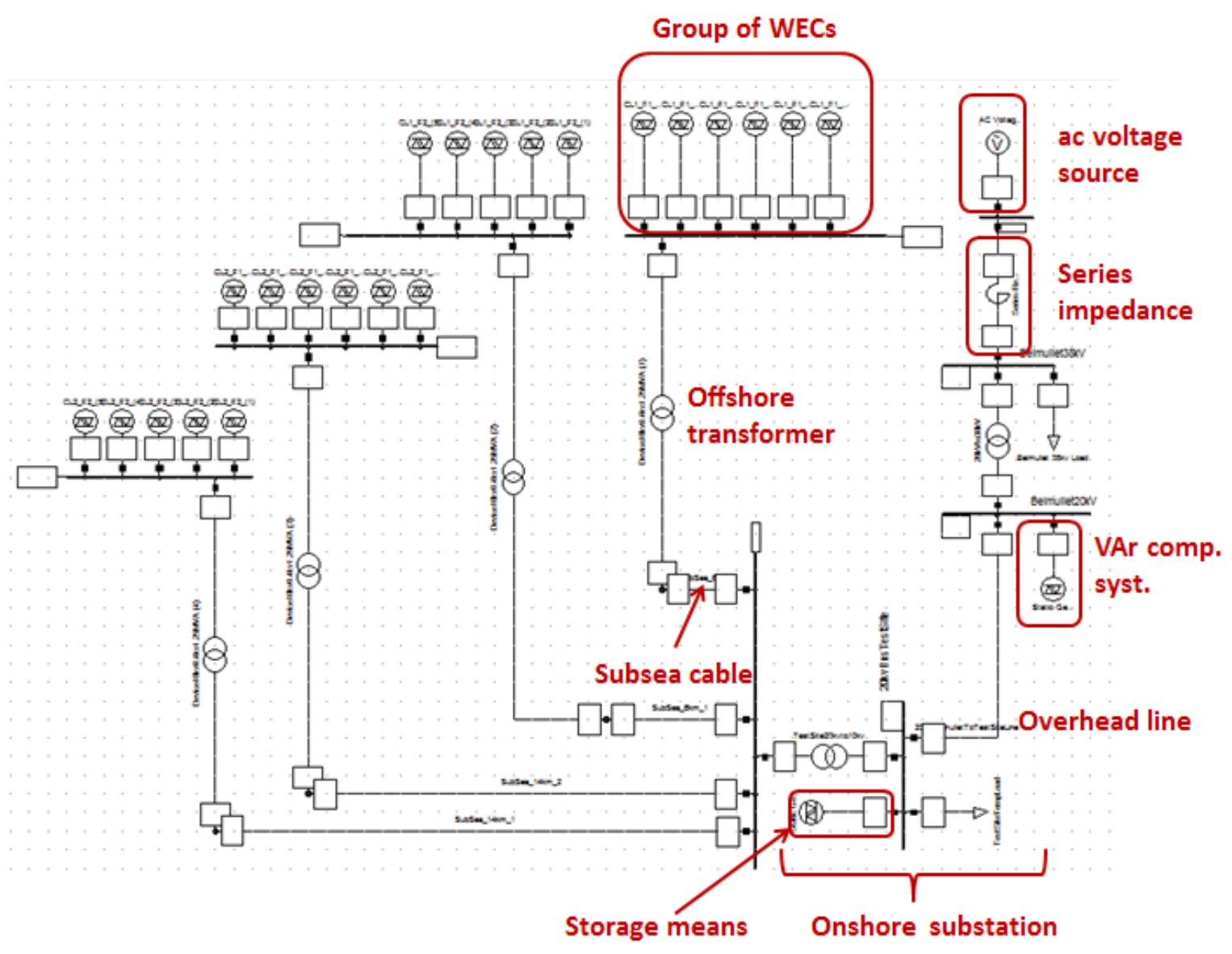

Figure 1: Schematic overview of the electrical network mode designed in PowerFactory

representative of, nor relevant to wave energy applications, considering the rapid current fluctuations generated by a wave farm compared to the very slow thermal dynamic response of a submarine cable, ranging usually between $2 \mathrm{~min}$ to 30 min [8], [12]. Consequently, a suitable current rating is expected to be much less than the maximum current level which the cables carry without leading to an excessive thermal loading, thus preventing a costly and useless over-rating. The second part of the study investigates the minimum current to which a submarine cable can be rated (under conditions that will be described in detail in the paper) from a thermal loading perspective. All simulations were performed under DIgSILENT power system simulator "PowerFactory".

\section{Modelling}

\section{A. Electrical network}

The wave farm network model was inspired from the main characteristics of the national wave test site of Ireland located off Belmullet [13], which is also similar to most of the other test sites currently in operation or under development. This site will be connected to a particularly weak network having a short-circuit level $S_{S C}$ estimated at $63 \mathrm{MVA}$ and an impedance angle $\Psi_{k}$ equal to $69^{\circ}$ in a previous study [1]. The farm is supplied by four submarine cables, two being $6.5 \mathrm{~km}$ long and the two others being $16 \mathrm{~km}$ long. Their capacitance and series impedance values are based on the cabling design studies performed at HMRC in conjunction with the site developer ESBI. An onshore substation, connected to the common point of coupling (PCC) to the rest of the network through a $5 \mathrm{~km}$ overhead line, steps the voltage up from $10 \mathrm{kV}$ to $20 \mathrm{kV}$. A $0.1 \mathrm{MVA}$ load operated at 0.95 lagging power factor represents its consumption, and a generic storage means, described more in detail in Section II-D, is intended to smooth the farm's power output before it is injected into the grid. The point of common coupling is located at the low voltage side of the $20 / 38 \mathrm{kV}$ transformer, to which a VAr compensation system is also connected. This latter piece of equipment maintains power factor at a fixed value, equal to unity in the base case, according to typical grid operators' requirements. Simulations were also performed to study the influence of different values of the reference power factor on flicker level. A $2.1 \mathrm{MVA}$ load, also operated at 0.95 lagging power factor, located on the high voltage side of the $20 / 38 \mathrm{kV}$ transformer, represents the consumption of a small size town of few thousands inhabitants.

Figure 1 shows a schematic overview of the grid model designed in PowerFactory including the wave farm's internal 


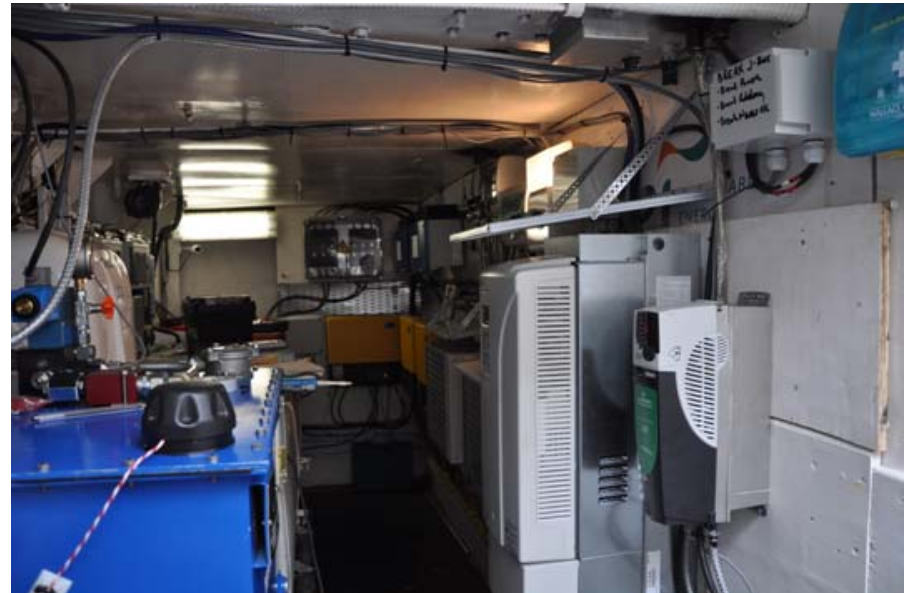

(a) On-board operating and monitoring system

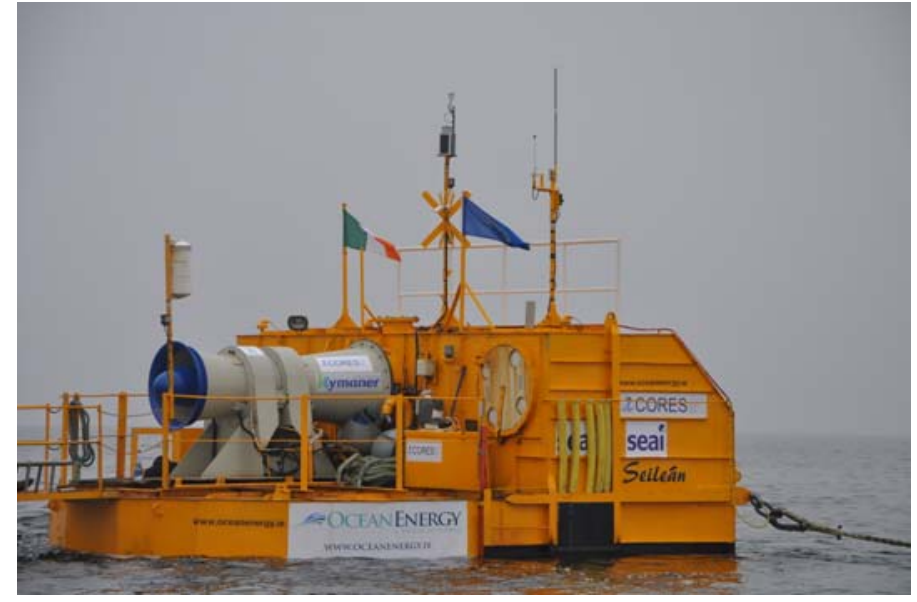

(b) CORES OWC deployed in Galway Bay, Ireland

Figure 2: Photos of the CORES OWC deployed at sea

network and the rest of the national/regional power system, modeled as a $38 \mathrm{kV}$ voltage source in series with an impedance. The reactance and the resistance of this series impedance simulate different short-circuit levels $S_{S C}$ and impedance angles $\Psi_{k}$, both of which are determining criteria regarding the strength of a network. A weak grid, whose power quality is more prone than a stronger grid to be negatively affected by the injection of power fluctuations, is usually characterized by a low value of either its short-circuit level $S_{S C}$ or impedance angle $\Psi_{k}$, or both. However, the strength of a given grid is relative to the characteristics of the injected power fluctuations. The ratio of the short-circuit level $S_{S C}$ to the farm's maximum power $S_{\text {farm }}$ is thus a more relevant criteria. The flicker study was conducted for several values of this ratio ranging between 3 (corresponding to a weak grid) and 15 (corresponding to a moderately strong grid), and for four values of the impedance angle $\Psi_{k}: 30^{\circ}, 50^{\circ}, 70^{\circ}$ and $85^{\circ}$, as defined in IEC standard 61400-21.

\section{B. Wave device power output}

Experimental data in the form of electrical power output time series was provided as an outcome of the project CORES, standing for "Components for Ocean Renewable Energy Systems". This FP7 European collaborative research project focused on the development of new concepts and components for power take-off, control, moorings, risers, data acquisition and instrumentation for floating wave devices [14]. The project itself was based on a floating OWC (oscillating water column) device and spanned over more than 3 years, between April 2008 and December 2011. The quarter-scale OWC prototype used in the project was deployed offshore from March to May 2011.

The device was connected to a small on-board island grid independent from the national electrical network. Figure 2a shows the on-board operating and monitoring system.
The on-board grid was maintained by a fully-rated power electronic converter and generated power was used to charge the on-board battery system, or dumped in resistive load banks. A diesel generator was also included. Figure $2 \mathrm{~b}$ shows the OWC deployed offshore.

The project has allowed the ocean energy research community to gain significant practical experience in the deployment, operation, and maintenance of offshore ocean energy converters. It has also generated a considerable amount of time series data on a number of parameters, including electrical parameters at a high resolution of $0.1 \mathrm{~s}$. Contrary to most available data which is averaged over a sea-state, a season or even a year, the CORES electrical power time series data can be scaled and used directly for grid impact studies. The fullscale significant wave height $H_{s}$ and the zero-crossing period $T_{z}$ of the time series retained for this study are equal to $4.6 \mathrm{~m}$ and $8.4 \mathrm{~s}$ respectively. This production period corresponds to moderate sea state conditions with respect to the national wave test site of Ireland which benefits from one of the highest wave energy potential in Europe. However, it is also representative of a high energy sea state with respect to other sites presenting a milder sea climate. During this production period, the generator was operated in constant speed control mode which means that, unlike in variable speed operation, inertial energy storage by means of speed control is not available. As a result, mechanical power peaks are converted directly into electrical power peaks, which is expected to represent a worst case with respect to power quality impact.

\section{Extrapolation to a multi-device farm}

The wave farm is modeled based on 22 individual wave energy converters (WECs), leading to a full-scale rated power of 19.4 MW. These generators are assumed to be approximately aligned perpendicularly to the dominant wave direction, in order to optimize their energy capture. The power profile of 


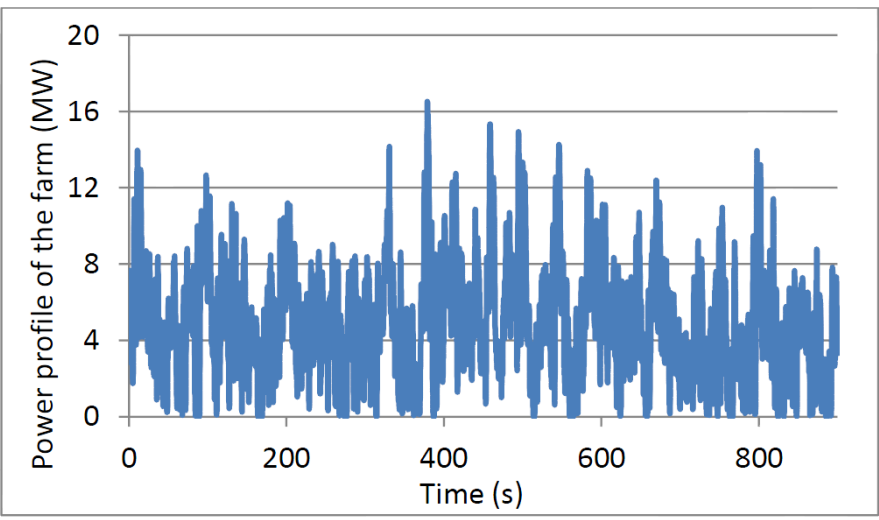

Figure 3: Wave farm's power profile for time delay set 1

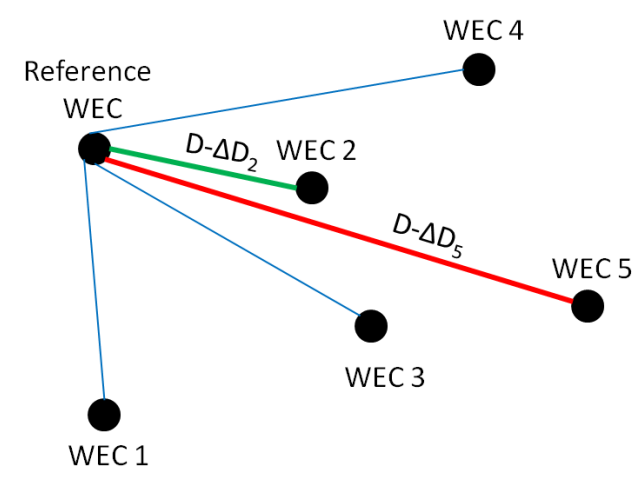

Figure 4: Schematic illustration of the spatial scattering method

each generator is based on the individual electrical power time series presented in Figure 3. A random time delay is applied to each generator's power profile but one, taken as the reference, in order to represent the effect of device aggregation on the power output of the farm. Each time delay $\Delta T_{\text {total }}$ consists of a constant time delay $\Delta T$ corresponding to a constant inter-WEC distance $D$, to which a variable time delay $\Delta T_{i}$ is subtracted. This latter time delay is intended to introduce a certain degree of randomness in the layout of the devices with the farm, and corresponds to a variable distance $\Delta D_{i}$, as shown in Figure 4. The inter-WEC distance $D$ is usually envisaged to be of the order of magnitude of hundreds of meters, ranging typically between $200 \mathrm{~m}$ and $500 \mathrm{~m}$ [15]. Each WEC group (that is, connected to the same submarine cable) consists of a maximum of 5 or 6 WECs which may not all be located side-by-side. Hence, the distance between the reference WEC and all the other WECs of the group can be as high as $D=1000 \mathrm{~m}$, to which the variable distance $\Delta D_{i}$, ranging between $0 \%$ and $60 \%$ of $D$ is subtracted. This leads to an inter-WEC distance $D-\Delta D_{i}$ ranging between $400 \mathrm{~m}$ and $1000 \mathrm{~m}$.

Time delays are calculated based on a typical value of the wave group speed $v_{g}$, estimated from the energy period $T_{e}$ of a given sea-state as follows [16]:

$$
\Delta T_{\text {total }}=\Delta T-\Delta T_{i}
$$

where

$$
\Delta T=\frac{D}{v_{g}}
$$

and

$$
\Delta T_{i}=\frac{\Delta D_{i}}{v_{g}}
$$

with

$$
v_{g}=\frac{g}{2 * 2 \pi f}
$$

where $v_{g}$ is estimated approximately as:

$$
v_{g}=\frac{g T_{e}}{4 \pi}
$$

The energy period $T_{e}$ of the ideal sinusoidal wave equivalent to the considered sea state and whose power can be expressed as $P=k H_{s}{ }^{2} T_{e}$ (where $k$ is constant), was used to estimate a reasonable value for the typical wave group speed $v_{g}$. Its use, more than this of more common parameters such as the peak period $T_{p}$ or as the zero-crossing period $T_{z}$, is justified as being more representative of the energy propagation speed between two WECs. This estimation method is thought to provide a reasonable order of magnitude for the typical speed of any wave group during a given sea-state.

The characteristic period $T_{z}$ for each production period, supplied as part of CORES data, is proportional to the energy period $T_{e}$ by a factor ranging between 0.71 and 0.83 at the Belmullet test site [17]. An average value of 0.77 was selected for the studies. Five different time delay sets were used in order to model five different device layout combinations. The maximum and minimum voltage values retained for the study are defined as the maximum and minimum values obtained over these five simulations respectively. In similar fashion, the maximum flicker levels retained for the study are the maximum values obtained over these five simulations as well.

\section{Storage means}

A generic storage means, intended among others to reduce flicker level, is placed at the onshore substation as indicated in Figure 1. It is modeled by means of a first order filter, as suggested in [18], taking the farm's power output $P_{G}$ as input and outputting a smoother power $P_{\text {storage, }}$ which can be expressed as:

$$
P_{\text {storage }}=P_{G} \frac{1}{1+s \tau}
$$

where $\tau$ is the storage means' time constant. Depending on the value of time constant $\tau$, the inertial response of a hydraulic accumulator (5 s), of a flywheel inertia (25 s) or of a seawater reservoir respectively (50 s) may be represented. 


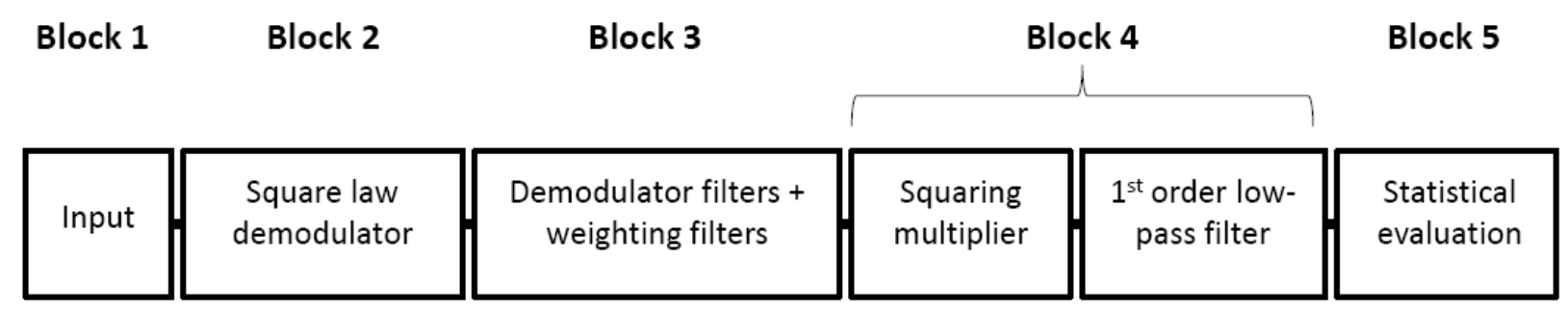

Figure 5: Functional representation of the IEC flickermeter

\section{FLICKER}

Applying a varying voltage on a light bulb can result in significant light intensity variations, thus causing a potential visual disturbance. Although it is normal that voltage may vary during the day, due for example to load switching or to motor starting, the impact of these fluctuations must be limited in order to avoid any disturbance to the customers. A statistical index of the short-term visual disturbance was developed in order to evaluate the level of annoyance caused by light intensity variations on the average individual. This index, called flicker severity or flicker level, is evaluated over 10 minutes and is named Pst. To ensure that visual disturbance remains negligible to the customer, grid operators limit either 1) the individual contribution in terms of flicker a power plant is allowed to emit 2) or the total flicker level at the point of common coupling.

Flicker is a phenomenon which can have heavy consequences on customers' comfort and health. It has been recognized since the 1960 s that flicker may potentially represent a risk to individuals prone to photosensitive epilepsy [19]. In addition, flicker can also induce electrical equipment malfunction, as well as non-negligible physical deterioration which may reduce significantly the lifetime of the equipment. According to [20], the performances of control systems using electronics drives have been reported to be significantly deteriorated by excessive and repeated voltage variations. In addition, the influence of these variations on rotating machines speed/torque control may for instance cause temperature rise and motor overloading issues. As wave farms can induce such rapid voltage variations with a significant amplitude, flicker is an issue of particular interest in the context of ocean energy grid integration.

\section{A. Evaluation}

Flicker level is usually evaluated with respect to the perception of light intensity variations based on an incandescent light bulb model [21]. This may represent a worst case scenario regarding a number of lighting equipment types such as LEDs or fluorescent lamps, given their lower flicker response to low-frequency voltage modulation [22], [23]. However, in the absence of widely agreed guidelines or standards on the flicker response of different types of lighting and electrical equipment, the recommendations established by IEC standard
61000-4-15 were retained for developing the flickermeter used in the studies presented in this paper.

\section{B. Flicker requirements}

The most stringent as well as the most permissive limits in terms of flicker level as enforced in different countries were investigated in [1]. It appeared that the most stringent limit is enforced in the Republic of Ireland where the flicker contribution of wave farms at the PCC is expected not to exceed 0.35 when they are connected at distribution level. The most permissive limit, enforced in several countries, regards the total flicker level and is equal to unity. These two limits were used as benchmarks for analyzing the simulation results.

\section{FlickERMETER DESIGN}

The computation of flicker level from voltage time series has been strictly defined in IEC standards 61000-4-15 and 61400-21 [24]. The former defines the overall design of a flickermeter while the latter describes few modifications to be brought to this design for the analysis of the flicker induced by wind farms. Flickermeters can be implemented either in a hardware or software form and compute flicker severity levels from voltage time series which may be generated either from field experiments or from numerical simulations.

A flickermeter consists of 5 functional blocks, as shown in Figure 5. Blocks 1 to 4 compute the instantaneous flicker level (i.e. flicker perceptibility) from voltage time series, while Block 5 computes the flicker level Pst.

In detail, by scaling down the r.m.s voltage amplitude to a per-unit value with respect to the time series mean r.m.s value, Block 1 extracts the fluctuations from the voltage time series. This also enables to generalize the use of the flickermeter for any voltage level. Luminous intensity produced by an incandescent light bulb for a given voltage fluctuation is then obtained by squaring the input voltage in Block 2 . Blocks 3 and 4 simulate the physical human perceptibility to light intensity variations by means of filters whose parameters were defined by means of experiments on groups of individuals. Sensitivity curves, also called perceptibility curves, were produced as an outcome of these experiments. Figure 6 illustrates this dependence of the sensitivity on frequency.

Human perceptibility is emulated by one filter reproducing the response of the eye to light intensity variations, while another simulates the brain reaction to the nervous signals 
Flicker perceptibility for a $230 \mathrm{~V}, 50 \mathrm{~Hz}$ lamp

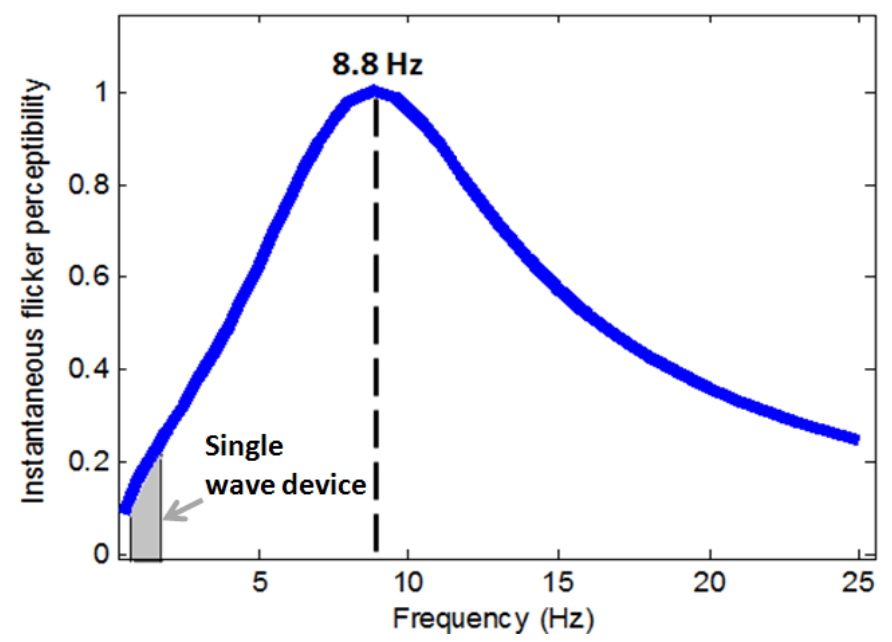

Figure 6: Flicker perceptibility curve

generated by the eye. The resulting filter included in Block 3 presents the following transfer function $F(s)$ :

$$
F(s)=\frac{k \omega_{1} s}{s^{2}+2 \lambda s+\omega_{1}^{2}} \frac{1+s / \omega_{2}}{\left(1+s / \omega_{3}\right)\left(1+s / \omega_{4}\right)}
$$

As small voltage variations are not taken into account accurately enough with the base design of the IEC 61000-4-15 flickermeter, IEC standard 61400-21 recommends to increase the number of classes of the classifier contained in Block 5 from 64 to 6400 for analyzing the flicker induced by wind farms. This number of classes seems suitable for wave energy applications as well, as shown in Table I which presents results of a test in which the short-term flicker level was computed based on five different number of classes.

\begin{tabular}{|c|c|c|c|c|c|}
\hline & \multicolumn{5}{|c|}{ Number of classes } \\
\hline & 64 & 3200 & 6400 & 12800 & 25600 \\
\hline Pst & 1.582 & 1.417 & 1.416 & 1.415 & 1.415 \\
\hline
\end{tabular}

Table I: Flicker level computed with several numbers of class

The flickermeter built for the purpose of this study includes the "empty class" feature designed by Alcorn [25] intended to help producing a sufficiently smooth cumulative probability function (CPF), which is necessary for obtaining sufficiently accurate results. It consists of interpolating the ordinate of any empty class based on the ordinate of surrounding non-empty classes. The calibration results demonstrated that a maximum flicker perceptibility equal to unity $( \pm 1 \%)$ is obtained by varying the amplitude of the input voltage fluctuations by maximum $-3 \%$ to $+2 \%$ of the indicative values provided in the standard, thus less than the maximum allowed voltage variations of $\pm 5 \%$. The compliance test results of Block 5 showed that the short-term flicker level remains within $\pm 5 \%$ of $P s t=1$ as required. Hence, the flickermeter can be considered as presenting a high level of accuracy.

\section{Methodology}

\section{A. Storage}

Simulations were performed with several values for the storage means' time constant $\tau$. Flicker at the point of common coupling was then investigated to determine the minimum value required in terms of time constant $\tau$ for which its level is maintained below the enforced limits.

\section{B. Cable rating}

The maximum current flowing through a cable appears to be no longer a relevant indicator for selecting a suitable rating for wave energy applications. This study investigated the dynamic thermal response of cables with different current ratings in order to determine the minimum current level for which a cable should be designed to avoid thermal overloading.

1) Introduction: The calculations are based on the recommendations of IEC standards 60287-1-1 [26] and 60287-2-1 [27]. This set of standards defines methods for determining the maximum current rating of a cable under steady-state conditions, with respect to a permissible temperature range $\Delta \theta$, and based on the thermal properties of the cable's components, as well as on the external conditions. A reverse approach was adopted in this study for determining the fictive instantaneous temperature rise $\Delta \theta(t)$ resulting from the application of a fluctuating current $I(t)$. The cable thermal dynamic response was modeled by filtering this temperature rise $\Delta \theta(t)$ by means of a first order low-pass filter whose time constant $\tau$ represents the cable's thermal response time. This parameter was selected as equal to $10 \mathrm{~min}$.

The cables' initial rating was selected based on a typical test site rated power $P_{\text {rated }}$ equal to $20 \mathrm{MW}$ as:

$$
I_{\text {rated }}=\frac{\frac{P_{\text {rated }}}{4}}{\sqrt{3} \mathrm{~V}}=\frac{\frac{20 \times 10^{6}}{4}}{\sqrt{3} \times 10 \times 10^{3}}=289 \mathrm{~A}
$$

The characteristics of the Nexans 2XS(FL)2YRAA RM cable were used for this study [28]. The cable includes three copper conductors insulated with cross-linked polyethylene (XLPE) and having each a copper screen. The sheath is made of polyethylene and the bedding of polypropylene yarn, as well as the serving. The surrounding armor is made of galvanized steel. Additional data necessary to perform the temperature rise calculations being however not indicated in the Nexans data sheet for this cable, it was estimated from information found in data sheets of other cables of similar structure, operating voltage and conductor size. As defined in IEC standard 60287$1-1$, the temperature rise $\Delta \theta(t)$ of a conductor above ambient temperature due to a constant current can be expressed as:

$$
\begin{array}{r}
\Delta \theta=\left(I^{2} R+\frac{1}{2} W_{d}\right) T_{1}+\left[I^{2} R\left(1+\lambda_{1}\right)+W_{d}\right] n T_{2} \\
+\left[I^{2} R\left(1+\lambda_{1}+\lambda_{2}\right)+W_{d}\right] n\left(T_{3}+T_{4}\right)
\end{array}
$$

where $I$ is the current flowing in one conductor (A), $R$ is the resistance per meter $(\Omega / \mathrm{m}), W_{d}$ is the dielectric loss per 
meter $(\mathrm{W} / \mathrm{m}), T_{1}, T_{2}, T_{3}$ and $T_{4}$ are the thermal resistances of different parts of the conductor $(\mathrm{K} . \mathrm{m} / \mathrm{W}), n$ is the number of conductors in the cable, $\lambda_{1}$ and $\lambda_{2}$ are the loss ratios in different parts of the conductor to the total losses in all the conductors.

The maximum permissible temperature was chosen equal to the operating temperature $\left(90^{\circ} \mathrm{C}\right)$. This represents a worst case scenario, considering that the cable is designed to be operated at higher temperatures for limited periods of time. It may also be interesting to note that by limiting the maximum permissible temperature to its nominal operating value, no additional thermal aging effect compared to the steady-state case due to excessive temperatures needs to be considered.

\section{RESUlts}

\section{A. Storage}

The storage means reduces considerably the voltage fluctuations at the point of common coupling even for values of the time constant $\tau$ as low as $1 \mathrm{~s}$. This is illustrated by Figure $7 \mathrm{a}$ in which the voltage profile at the PCC for a shortcircuit ratio equal to 3 is presented. Consequently, flicker is also dramatically reduced, as shown in Figure $7 \mathrm{~b}$ in which the flicker level for all the short-circuit ratio and impedance angle $\Psi_{k}$ values considered. Although the flicker level may exceed the most permissive limit for values of the impedance angle $\Psi_{k}$ up to $50^{\circ}$ for the connection points with the lowest shortcircuit ratio, a storage constant $\tau$ as low as $1 \mathrm{~s}$ is sufficient for reducing it below unity in this case. If the most stringent limit is enforced, then a storage constant $\tau$ of $3 \mathrm{~s}$ is required for the weakest grids. A storage constant $\tau$ equal to $1 \mathrm{~s}$ only is sufficient for reducing flicker below the most stringent limit for connection points whose impedance angle is equal to $70^{\circ}$ for the weakest grids. In particular, a storage means' time constant of $1 \mathrm{~s}$ would be sufficient for a wave farm connected at the AMETS test site to be compliant with the Irish flicker requirement. Connection points whose impedance angle is equal to $85^{\circ}$ and/or whose short-circuit ratio is greater than 15 do not require using a storage means to smooth the farm's power output as the flicker level obtained for this type of points is maintained below the most stringent limit in any case. In conclusion, a storage means of particularly low time constant $\tau$ may be sufficient for avoiding any flicker issue posed by the connection of a medium-size wave farm to a particularly weak grid. This corresponds to the typical time constant of a hydraulic accumulator or of a small size flywheel.

\section{B. Cable rating}

The results obtained from the dynamic simulations confirmed that the cable selected initially was clearly overrated with respect to the current time series considered in this study. First of all, it must be borne in mind that the maximum power flowing through the cable is equal to 3.4 MW (corresponding to $194 \mathrm{~A}$ ) whereas the cable was initially designed for a power capacity up to $5 \mathrm{MW}$ in each cable. However, even considering this aspect, the results indicated that the cable could be rated to a much lower level. Figure 8a shows that the temperature actually reached by the conductor for a thermal time constant $\tau$ equal to $10 \mathrm{~min}$, as well as the temperature predicted by the steady-state calculations, which simulate an instantaneous cable thermal response. The very important difference that exists between the two temperatures illustrates the lack of relevance of steady-state calculations regarding cables' thermal loading in the case of wave energy applications.

The maximum permissible temperature of the conductor, equal to $90^{\circ} \mathrm{C}$, is not exceeded for a conductor diameter greater than or equal to $2.6 \mathrm{~mm}$. This is much smaller than the diameter of the cable initially selected and equal to $8.2 \mathrm{~mm}$. The current rating corresponding to this diameter was estimated from the polynomial approximation of a curve linking the current ratings of similar cables to their conductor cross-sectional area. Available data for this curve was found in manufacturers data sheets [29], [31]. In order to improve the accuracy of the polynomial approximation, an ordinate in zero was added and approximated to zero, considering that the current level flowing through a conductor whose diameter converges to zero would also converge to zero. The resulting curve is shown in Figure 8b. The minimum current rating required for a submarine cable was found to be equal to 29.7 A. This represents only $15 \%$ of the maximum current flowing through the cable, equal to $194 \mathrm{~A}$, but represents $49 \%$ of the average current equal to $61.1 \mathrm{~A}$. This shows that the average current level is a relevant indicator for estimating the minimum cable rating.

However, the results described in this section must be considered pragmatically. In practice, the conductor diameter of available submarine cables for operation at this voltage level is usually greater than or equal to $8.2 \mathrm{~mm}$, which is much greater than the recommended diameter values. However, although the results obtained for an approximately $20 \mathrm{MW}$ wave farm can be considered as "fictive", the methodology developed as part of this work may be applied to cables included in wave farms of greater rated power. As mentioned previously, estimating the minimum cable rating more accurately with respect to wave energy applications may lead to a significant decrease in terms of capital expenditure.

\section{CONCLUSIONS}

This paper presented an analysis intended to determine the characteristics required from a storage means for maintaining the flicker level at the point of common coupling below the most permissive as well as the most stringent limits enforced in a number of countries. The storage means was modeled generically by means of a first order low-pass filter of time constant $\tau$. The minimum value required for this time constant $\tau$, when necessary, was demonstrated to range between $1 \mathrm{~s}$ and $3 \mathrm{~s}$, indicating that a hydraulic accumulator or a small flywheel may be used in this case. In particular, the connection of a wave farm to the AMETS test site proved 


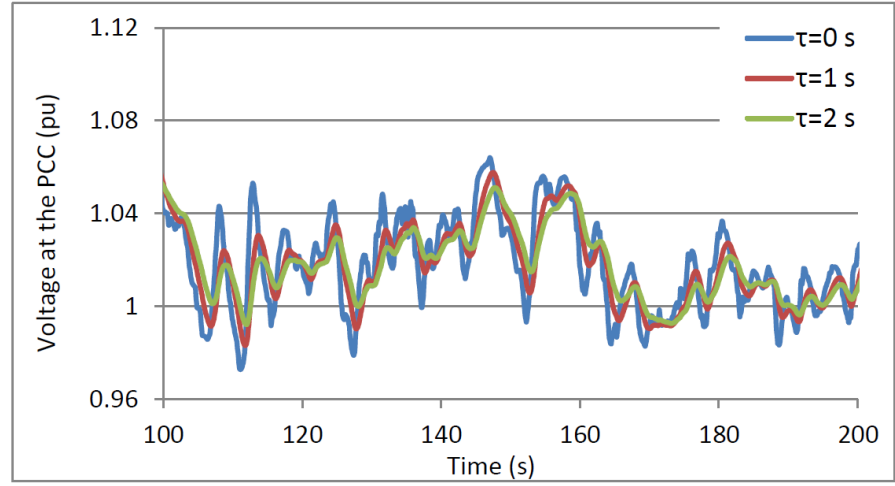

(a) Voltage profile

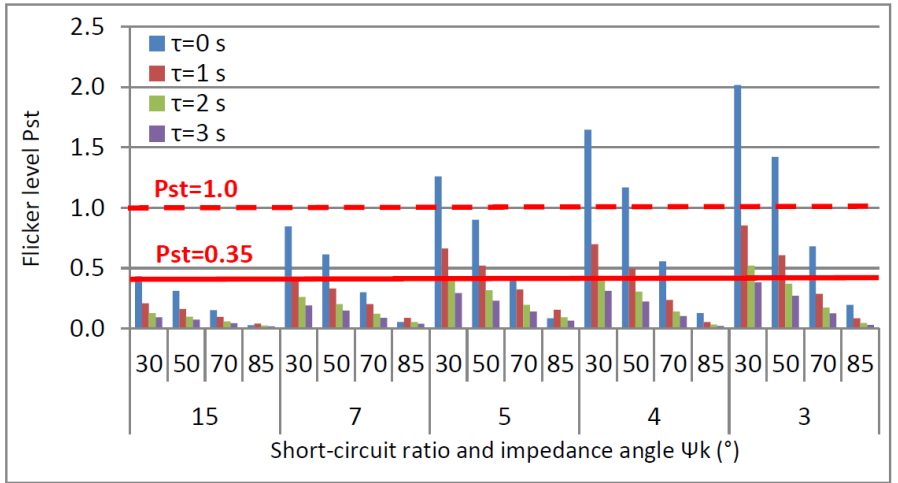

(b) Flicker level

Figure 7: Voltage profile and flicker level for several values of the storage means' time constant $\tau$

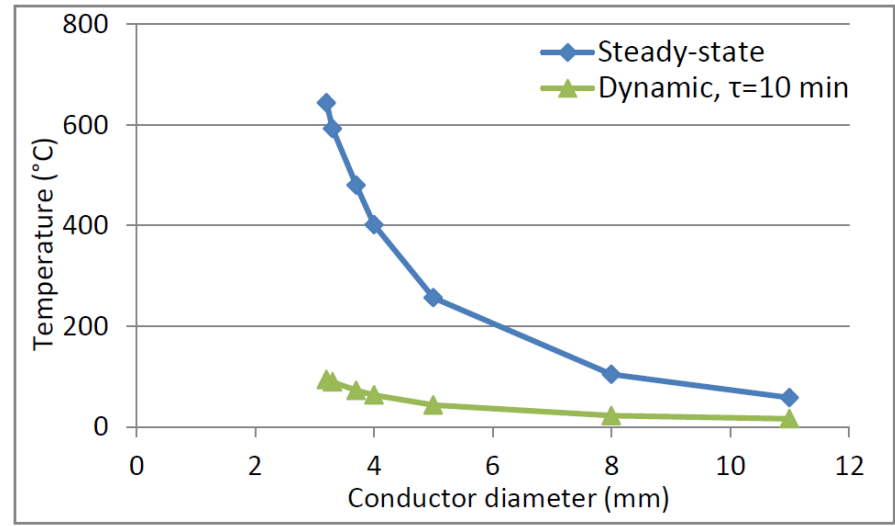

(a) Temperature $\left({ }^{\circ} \mathrm{C}\right)$

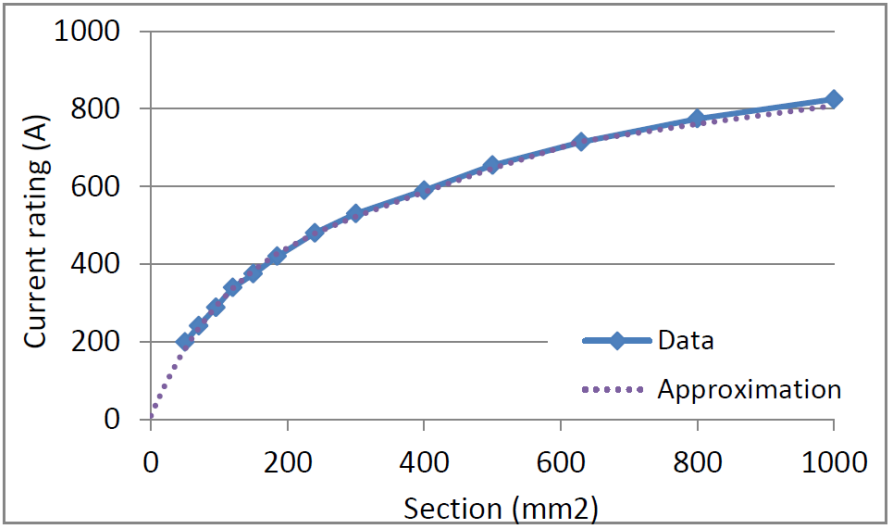

(b) Typical cable current rating (A)

Figure 8: Temperature as a function of the conductor diameter and typical cable rating as a function of the conductor crosssectional area

to necessitate the use of a storage means whose time constant $\tau$ is at least equal to $1 \mathrm{~s}$.

This study investigated also the minimum current rating required for a submarine cable, taking into account its thermal response time. A methodology was developed as part of this work and was presented in this paper. It was demonstrated that the average current level was a relevant indicator for determining the minimum current rating required for a submarine cable. More specifically, the results presented in this paper showed that the current rating obtained through this method is equal to $49 \%$ of the average current.

The study concluded that although cables of smaller ratings could be used with respect to the operating conditions considered for the study, such small size cables were not available on the market. However, the methodology developed as part of this work is expected to be very relevant for analyzing the minimum current rating of cables included in wave farms of greater power capacity. As mentioned previously, estimating the minimum cable rating more accurately with respect to wave energy applications may lead to a significant decrease in terms of capital expenditure.

\section{ACKNOWLEDGMENT}

The authors wish to acknowledge the FP7 project CORES, RCN 41815. Financial support from Science Foundation Ireland through the Charles Parsons Initiative is also acknowledged.

\section{REFERENCES}

[1] A. Blavette, D L. O'Sullivan, A. W. Lewis, M. G. Egan, "Impact of a Wave Farm on its Local Grid: Voltage Limits, Flicker Level and Power Fluctuations", 2012 Proc. IEEE/MTS OCEANS12 Conf., Yeosu, South Korea.

[2] A. Nambiar, A. Kiprakis, D. Forehand, and A. Wallace, "Effects of array configuration, network impacts and mitigation of arrays of wave energy converters connected to weak, rural electricity networks", 2010 Proc. 3rd International Conference Ocean Energy, Bilbao, Spain.

[3] D. O'Sullivan, F. Salcedo, A. Blavette, M. Santos, A.W. Lewis, "Case studies on the benefits of energy storage for power quality enhancement: oscillating water column arrays", 2012 Proc. 4th International Conference on Ocean Energy, Dublin, Ireland. 
[4] M. Santos, A. Blavette, E. Tedeschi, D. O’Sullivan, F. Salcedo, "Case Study on the benefits of energy storage for power quality enhancement: point absorber arrays", 2012 Proc. 4th International Conference on Ocean Energy, Dublin, Ireland.

[5] J. Aubry, "Optimisation du dimensionnement d'une chaîne de conversion électrique directe incluant un système de lissage de production par supercondensateurs. Application au houlogénérateur SEAREV', PhD thesis, Ecole Nationale Supérieure de Cachan, France, 2011.

[6] Econnect and National Grid, "Round 3 Offshore Wind Farm Connection Study", a report prepared by econnect and National grid for the Crown Estate, 2009.

[7] F. Sharkey, E. Bannon, M. Conlon, K. Gaughan, "Dynamic electrical ratings and the economics of capacity factor for wave energy converter arrays", in 2011 Proc. of the 9th European Wave and Tidal Energy Conference, Southampton, UK.

[8] R. Adapa, and D. Douglass, "Dynamic thermal ratings: monitors and calculation methods", in Power Engineering Society Inaugural Conference and Exposition in Africa, IEEE, p.163-167, 2005.

[9] S. Foss, R. Maraio, "Dynamic line rating in the operating environment", IEEE Transactions on Power Delivery, Vol. 5, No. 2, April 1990

[10] J. Orsigova, P. Toman, "Application of thermal models of digital protective relays in cable protection"

[11] W. Torre (San Diego Gas and Electric), "Dynamic circuit thermal line rating, Consultant report for the California Energy Commission”, October 1999

[12] J. Hosek, "Dynamic thermal rating of power transmission lines and renewable resources", ES1002 : Workshop March 22nd-23rd 2011.

[13] Website of the SEAI, http://www.seai.ie/, Accessed in September 2012.

[14] F. Thiebaut, D. O'Sullivan, P. Kracht, S. Ceballos, J. Lopez, C. Boake, J. Bard, N. Brinquete, J. Varandas, L.M.C. Gato, R. Alcorn, A.W. Lewis, "Testing of a floating OWC device with movable guide vane impulse turbine power take-off", 2011 Proc. 9th European Wave and Tidal Energy Conference, Southampton, UK.

[15] A. Babarit, "Impact of long separating distances on the energy production of two interacting wave energy converters", Ocean Engineering, Volume 37, Issues 8-9, June 2010, Pages 718-729.

[16] J. Falnes, "Ocean Waves and Oscillating Systems: Linear Interactions Including Wave-Energy Extraction", Cambridge University Press, 2002.

[17] B. G. Cahill, T. W Lewis, "Wave energy resource characterization of the Atlantic Marine Energy Test Site", 2011 Proceedings of the 9th European Wave and Tidal Energy Conference, Southampton, UK.
[18] D. O'Sullivan, D. Mollaghan, A. Blavette and R. Alcorn (2010) "Dynamic characteristics of wave and tidal energy converters \& a recommended structure for development of a generic model for grid connection", a report prepared by HMRC-UCC for the OES-IA Annex III. [Online], Available: www.iea-oceans.org.

[19] E. Ossentjuk, C.J.O. Elink Sterk, W. Strom van Leeuwen, "Flickerinduced cardiac arrest in a patient with epilepsy", Electroencephalography and Clinical Neurophysiology, Volume 20, Issue 3, March 1966, Pages 257-259

[20] "Signal Processing of Power Quality Disturbances", edited by M. Bollen, I. Gu, published by John Wiley \& Sons, 2006.

[21] IEC standard 61000-4-15, "Electromagnetic compatibility (EMC) - Part 4-15: Testing and measurement techniques - Flickermeter - Functional and design specifications ", 08-2010.

[22] C. Rong, J. Cobben, J. Myrzik, J. Blom, W. Kling, "Flickermeter used for different types of lamps", 2007 Proceedings of the 9th International Conference on Electrical Power Quality and Utilisation

[23] W. Heffernan, L. Frater, and N. Watson, "LED Replacement for Fluorescent Tube Lighting", Proceedings of the 2007 Australasian Universities Power Engineering Conference

[24] IEC standard 61400-21, "Wind turbines - Part 21: Measurement and assessment of power quality characteristics of grid connected wind turbines", ed2.0 (2008-08)

[25] R. Alcorn, "Wave Station Modelling Based on the Islay Prototype Plant", PhD Thesis, Queen's University Belfast, UK, 2000.

[26] IEC standard 60287-1-1, "Electric cables : Calculation of the current rating. Part 1-1: Current rating equations (100\% load factor) and calculation of losses", ed.2.0, 12-2006

[27] IEC standard 60287-2-1, "Electric cables - Calculation of the current rating - Part 2: Thermal resistance - Section 1: Calculation of thermal resistance", ed1.2 Consol. with am1\&2, 05-2006

[28] Nexans data sheet, technical reference: 2XS(FL)2YRAA RM 12/20 (24) $\mathrm{kV}, 3$ core XLPE-insulated cables with PE sheath and armouring, longitudinally and radially watertight, PDF document generated on request on 12th November 2012.

[29] Nexans power cable data sheet, Submarine cable $10 \mathrm{kV}, 6 / 10$ (12)kV 3 core Copper XLPE cable, Cu-screen, Al/PE-sheath, Armouring

[30] Universal Cable catalogue, XLPE insulated power cables

[31] ABB booklet, XLPE Submarine Cable Systems Attachment to XLPE Land Cable Systems - User's Guide, rev.5 